\title{
ДИСКУССИИ
}

\section{За и против регулирования финансовых пузырей монетарными методами}

\author{
Чиркова Е.В. 5
}

В данной статье обсуждаются негативные последствия финансовых пузырей и иелесообразность их монетарного регулирования. Плюсы и минусы возможных ответов монетарных властей на надувание финансового пузыря и поведение регулятора во время последующего коллапса пузыря разбираются с учетом доступности и эффективности инструментов регулирования, возможных негативных последствий и экстерналий той или иной тактики, а также возможностей регулятора по идентификации пузырей.

JEL: $G 10$

Ключевые слова: государственное регулирование, монетарная политика, иентральный банк, финансовый пузырь, процентная ставка, моральный риск.

\section{1. Негативные последствия финансовых пузырей}

Финансовые пузыри, особенно макроэкономического характера, могут иметь неприятные экономические и социальные последствия. Во-первых, они серьезно влияют на реальный сектор: в период бума они способствуют возникновению перегрева в реальной экономике. Это выливается в перекосы (отраслевые дисбалансы) в развитии реального сектора, выражающиеся, в том числе, и в переинвестировании («закопанных инвестициях»), что неизбежно ведет к потере благосостояния в долгосрочной перспективе. Примером избыточного инвестирования является прокладка трансатлантических оптико-волоконных сетей во время технологического бума второй половины 1990-х: в момент окончания бума необходимая мощность была превышена в 10 раз. Передача данных по Интернету между Америкой и Евразией резко удешевилась, что способствовало развитию аутсорсинга таких услуг, как колл-центры и проч. в Индии, но большая часть инвестиций не оправдала себя. Деньги были закопаны в прямом и переносном смысле. Например, разорилась компания Global Crossing - один из основных игроков на этом поле. Ее инвестиции в кабель в ходе процедуры банкротства были проданы примерно за 1/20 долю от того, что было вложено: сеть, включавшая 20900 км. кабеля с глубоководным залеганием ${ }^{6}$ и четыре наземные станции, строительство которой было завершено в 2000 году и обошлось в 1,35 млрд долл., в 2003 году в ходе процедуры банкротства была продана фонду прямых инвестиций за 65 млн.

Во время макропузырей, как правило, оказываются завышенными цены на недвижимость и землю. Это может привести к торможению развития инфраструктуры, например строительства автомобильных дорог, так как очень дорогим становится выкуп земли. При том что отдельные игроки, например спекулянты на фондовом рынке, богатеют, качество жизни среднего человека может понизиться. Самый яркий пример - японское экономическое чудо, закончившееся в конце 1980-х, во время которого цены на квартиры в Токио возросли так, что люди были вынуждены селиться далеко от города и тратить на дорогу на работу по три часа в каждую сторону (и это при наличии скоростных поездов). Кроме того, резко снизилась рождаемость, так как многие семьи не могли себе позволить

${ }^{5}$ Канд. эконом. наук, доцент кафедры экономики и финансов фирмы экономического факультета НИУ-ВШЭ.
${ }^{6}$ Две линии между Западным побережьем США и Японией. 
купить даже самую дешевую квартиру - ипотеку давали на несколько поколений.

Негативные последствия пузырей состоят и в том, что реальная экономика в период краха пузыря сжимается еще больше, чем могла бы упасть в случае отсутствия пузыря, и происходит это из-за дестабилизации финансового сектора, который характеризуется удорожанием кредита, кризисом ликвидности, доминированием негативных ожиданий. Так, разброс оценок, сделанных учеными-экономистами насчет того, насколько завышены в цене были акции в августе 1929 года в США, варьирует от 0 до 50\% (Barksy, De Long, 1990; De Long, Shleifer, 1991; Donaldson, Kamstra, 1996; McGrattan, Prescott, 2003; Napier 2007; Rappoport, White, 1993; Sirkin, 1975; White, 1990), тогда как падение фондового рынка в 1929-1932 годах составило 89\% от пиковой стоимости. Развитие ситуации шло по принципу самораскручивающейся спирали: первоначальное, относительно небольшое, падение акций вызвало сокращение реального производства, а это, в свою очередь, - дальнейшее падение фондового рынка, и т.д. Депрессия была преодолена только с началом Второй мировой войны.

Наконец, сжатие пузыря, особенно если это был охватывавший экономику в целом макропузырь, может вести к массовым банкротствам компаний реального сектора, банков, брокеров, инвесторов и спекулянтов, как быков, так и медведей, иными словами - к финансовой нестабильности. Как подмечает Фабер, «лишь немногие выходят из спекулятивной мании без убытков. Медведи обычно легко ранены, поскольку они показывали худшие результаты, пока рынок шел вверх, или погорели на том, что слишком рано открыли короткие позиции, тогда как быки просто уничтожены, поскольку они слишком долго оставались оптимистами, слишком долго» (Faber 2008). Накопления теряют не только сами спекулянты, но и незащищенные слои населения, не принимавшие никакого участия в истерии (например, вкладчики пенсионных фондов). Однако сжатие пузыря приводит к финансовой нестабильности отнюдь не всегда, и некоторые ученые как раз и предлагают именно этот фактор принимать во внимание при принятии решения, поддерживать инвесторов или нет (Mishkin, White). Кроме того, крах, которым неизбежно заканчивается пузырь, как правило, ведет к повышению процентных ставок и сокращению инвестиций.

\section{2. Возможная роль государства в регулировании пузырей: основные вопросы}

Регулирование пузырей со стороны государства может вестись по нескольким направлениям. В последние годы все больше говорят и о том, что нужно ужесточать и регулирование банков, например повышать нормативы резервирования средств, требовать использования широкого спектра показателей для оценки рисков, а не только популярного нынче показателя VAR (value-at-risk) ${ }^{7}$. Сдерживанию пузырей может способствовать и политика регулирования фондового рынка. Хорошим примером является, например, создание в США после краха 1929 года Комиссии по ценным бумагам и биржам и принятие ею требований по марже - доле заемных средств, которые могут использоваться при покупке акций. Когда этот норматив только вводился после краха 1929 года, он составлял 75\% (три четверти своих, четверть заемных), впоследствии был понижен до 50\% и остается на этом уровне на сегодняшний день. Сдерживать пузыри можно и налоговой политикой: так, например, в Великобритании недавно были введены прогрессивные налоги на высокие бонусы инвестиционных банкиров.

Одним из важнейших инструментов регулирования финансовых пузырей является монетарная политика. На действиях монетарных властей мы и остановимся подробнее в данной статье.

\footnotetext{
7 Дело не только в том, что этого показателя недостаточно, а и в том, что использование идентичных показателей всеми игроками ведет к унификации мнений относительно цен на активы, что может способствовать надуванию пузыря.
} 
Вопрос о роли государства в раздувании или сдерживании пузыря через денежную политику или политику «поддержки» инвесторов очень важен, ибо некорректное регулирование может иметь нешуточные последствия не только для рынков, но и для экономики в целом.

Основные вопросы, которые задаются в связи с монетарным регулированием пузырей, следующие:

• Должно ли регулирование цен на активы входить в список целей монетарных властей в принципе?

- Имеется ли для этого достаточный инструментарий?

- Должны ли власти хотя бы предупреждать инвесторов, что на рынке надулся пузырь?

- Если ставить задачу регулировать цены на активы, то в какой стадии надувании пузыря это делать:

- регулировать превентивно, чтобы пузырь не надулся в принципе;

- начинать действовать, когда его признаки уже имеют место;

- или вступать в игру, только когда пузырь начал сдуваться?

- Что предпочтительнее, когда пузырь наличествует: осторожно проткнуть его или, наоборот, сдерживать падение?

\section{3. Возможные действия монетарных властей, когда финансовый пузырь надувается}

На тему того, какой должна быть политика государства, если оно видит, что надувается пузырь, существует обширная научная литература, а также многочисленные заявления глав центробанков.

Считается, что возможно четыре варианта действий центробанка в отношении надувания пузыря:

• ничего не делать;

• стараться поддерживать целевой уровень цен на активы, то есть сдерживать надувание пузыря достаточно активно и жестко;

- мягко действовать в противоход (по-английски leaning against the wind, плыть против течения);

• «протыкать» пузырь (данная точка зрения называется еще ликвидационной).

Еще в 1990-е годы ученые полагали, что задачей центральных банков может быть таргетирование инфляции или экономического роста или поддержание баланса между тем и другим, достигаемое через регулирование процентной ставки, но цены на активы не должны регулироваться. По мнению нынешнего главы Европейского центробанка Жана Клода Трише (Jean-Claude Trichet), сейчас такой подход считается ортодоксальным (Trichet, 2005), однако ему лично, как будет показано ниже, он близок.

После краха интернет-пузыря экономисты все больше задаются вопросом: а не должен ли центральный банк каким-то образом участвовать в ценообразовании на активы (акции, недвижимость), иными словами, сдерживать раздувание пузырей, чтобы избежать кризисов, связанных с их схлопыванием? Понятно, что процентная ставка, которая регулируется центральными банками всегда, - это не дискуссионный вопрос, сама по себе влияет на стоимость активов, например, через влияние на норму дисконта, - чем она ниже, тем активы дороже, и наоборот. Поэтому еще грамотнее поставить вопрос так: а не должен ли центробанк, устанавливая процентную ставку в целях регулирования инфляции и/или экономического роста, учитывать и возможные последствия с точки зрения цен инвестиционных активов? Этот вопрос хоть и задается все чаще, однако ответ на него с течением времени не меняется: несмотря на мнение Трише об ортодоксальности такого подхода, большинство зарубежных ученых и высокопоставленных политиков-финансистов продолжают склоняться к тому, что не должен.

Так, Бен Бернанке (Ben Bernanke) в своей статье, написанной им совместно с Марком 
Гертлером (Mark Gertler), «Должны ли центробанки реагировать на движение рыночных цен?» («Should Central Banks Respond to Movements in Asset Prices?» (Bernanke, Gertler, 2001), опубликованной в 2001 году, когда Бернанке еще не был главой Федеральной резервной системы США, утверждал: «Изменения в ценах активов должны влиять на монетарную политику только с точки зрения прогноза инфляции...». И это не просто лозунг. Бернанке и Гертлер провели ряд исследований, в которых они моделировали, что будет, если центральные банки начнут контролировать и цены активов тоже. Согласно предлагаемой ими модели, проку будет мало - если это и даст кой-какой эффект с точки зрения влияния на экономический рост, то совсем небольшой, а инфляцию такие действия могут только подстегнуть ${ }^{8}$.

Алан Гринспен, осмысливая корректность своих действий как главы Федеральной резервной системы США (ФРС) во время мании доткомов в конце 1990-х, пришел к выводу о том, что совершенно неочевидно, что пузырь, даже идентифицированный на ранней стадии, может быть купирован монетарными властями без того, чтобы вызвать падение реальной экономической активности. А такого исхода необходимо избегать. В лучшем случае надувание пузыря может быть отсрочено, но оно неизбежно, так как связано с изменением отношения инвесторов к риску, которое одной монетарной политикой изменить нельзя. Гринспен приводит следующие примеры: фондовый рынок США продолжал расти после повышения учетной ставки на 300 пунктов за год, закончившегося в феврале 1989 года; когда за год, начиная с февраля 1994 года, учетная ставка была повышена на 300 пунктов, рынок сначала припал, но вскоре возобновил свой рост; с середины 1999-го по май 2000 года учетная ставка была повышена на 150 базисных пунктов, а рост фондового рынка так и не был остановлен (Greenspan, 2002).

Трише в своих выступлениях подчеркивает, что «мы должны быть максимально осторожными» в вопросе регулирования цен на активы, поскольку установление процентной ставки в зависимости от цен на активы - «это открытие ящика Пандоры», а, кроме того, оценка справедливости уровня цен - очень сложная задача (Trichet, 2003). Он выступает против регулирования цен на активы, так как не сомневается, что главной задачей центробанка по-прежнему остается таргетирование инфляции и экономического роста, цены активов определяются в большей степени изменением фундаментальных факторов, нежели инфляцией, а роль регулирования цен на активы в обуздании инфляции невелика. Или даже хуже: если монетарная политика будет зависеть от цен на активы, а те от будущей монетарной политики, то инфляция может стать и вовсе нерегулируемой (по-английски этот феномен называется inflation indeterminacy - неопределимость инфляции) и очень волатильной (Trichet, 2005).

Что касается действий в противоход, то есть постепенного увеличения учетной ставки по мере надувания пузыря, то здесь нужно учитывать, что отрицательный шок, скорее всего, будет иметь больший эффект, чем положительный. По мнению Трише, плыть против течения можно, только если соблюдаются следующие условия: нет непосредственной угрозы резкого краха, цены активов чувствительны к процентной ставке (как показал опыт Гринспена, это далеко не всегда так), а потери от раздувания пузыря (например, в виде перекосов в экономике, которые обсуждались выше) существенны. Симметричная реакция центробанка - ужесточение денежной политики в период бума и ослабление в период депрессии - не поощряет рисковое поведение игроков и снижает избыточное инвестирование во время бума, что хорошо. С другой стороны, при глобализации экономики маловероятно, чтобы действия центробанка одной страны или экономической зоны существенно повлияли

\footnotetext{
${ }^{8}$ Кроме того, Бен Бернанке в соавторстве с другим ученым - Кеннетом Кютнером (Kenneth Kutner) - оценил масштаб влияния на цены акций изменений в процентной ставке и получил, что понижение ставки на $0,4 \%$ ведет к росту цен акций на 1\% (Bernanke, Kutner, 2005). Обратный эффект не тестировался. К сожалению, эти данные не дают четкого ответа на вопрос, каким же должно быть изменение процентной ставки, чтобы сдуть пузырь: понятно, что изменения должны быть очень серьезными, а при больших колебаниях эластичность изменения цен может резко измениться.
} 
на цены активов вопреки мировому тренду (Trichet, 2005). Что касается практики, то, как находят ученые, политика под названием «плыть против течения» применяется в реальной жизни: так, по данным Ригобон и Сак (Rigobon, Sack, 2003), рост (падение) индекса S\&P на $5 \%$ повышает вероятность повышения (понижения) процентной ставки наполовину.

Роберт Рубин, глава Казначейства США во времена администрации Билла Клинтона, в своих мемуарах задается вопросом: а должен ли политик даже просто предупреждать инвесторов, если он видит, что на рынке пузырь? - и отвечает, почему, по его мнению, не должен: «Предупреждение инвестирующей публики может показаться заманчивым, но я думал и до сих пор думаю, что государственные служащие не должны комментировать уровень фондового рынка - и это касается ситуаций, когда фондовый рынок кажется недооцененным по отношению к историческим уровням, и в равной степени, когда он представляется переоцененным» (Rubin, Wesberg, 2004). Он видит четыре причины для этого: «Во-первых, каким бы ни было наше мнение, никто не может сказать, каков “правильный” уровень фондового рынка и переоценен ли рынок... Во-вторых, я думаю, что любые мои комментарии не возымели бы эффекта. Урок был нам преподан 5 декабря 1996 года, когда Алан Гринспен задал в своей речи риторический вопрос: “Но как узнать, в какой момент иррациональное возбуждение неоправданно вознесло цены активов, которые потом упадут, внезапно и надолго?..” Я не уверен, что Алан намеревался высказаться насчет уровня фондового рынка. Но рынки решили, что фраза "иррациональное возбуждение" была употреблена специально, и на следующий день Доу упал с 6437 до 6382 пунктов. А потом бычий рынок возобновил движение и поднялся еще на 5000 пунктов... ${ }^{9}$ В-третьих, я считал, что попытки повлиять на финансовые рынки словами не только будут неэффективны, но они еще и подорвут доверие к говорящему, поскольку знающие люди понимают, что у него нет никакого особого видения, и потому, что он наверняка будет неправ в большинстве случаев... Наконец, постепенное падение переоцененного фондового рынка может быть “переварено" инвесторами спокойно. Но если комментарий официального лица по какойлибо причине вызовет существенное падение рынка, это может быть для экономики разрушительным» (Rubin, Wesberg, 2004). Мы согласны с тезисами Рубина полностью.

Алан Гринспен также придерживается мнения, что трудно судить о наличии пузыря до того, как он сдуется, и еще труднее повлиять на действия игроков. В своем выступлении перед конгрессом США в 1999 году он заявил, что утверждение о том, что на рынке пузырь, равносильно утверждению, что «сотни информированных инвесторов все оценивают неправильно» (Greenspan, 1999). А в своих мемуарах Гринспен признается: «Действительно, я пришел к выводу, что мы никогда не сможем с полной уверенностью диагностировать иррациональное возбуждение до коллапса, еще в меньшей степени мы способны действовать по этому поводу» (Greenspan, 2008).

Если в 1996 году Гринспен публично утверждал, что на рынке - пузырь, то в 1998 году он защищал еще более высокие уровни цен. Как пишет известный макроэкономист Роберт Бреннер, в 1998 году Гринспен «видел мало причин оспаривать логику взрывного роста фондового рынка. На самом деле еще с прошлой весны Гринспен публично провозглашал наступление эры “Новой экономики”, в которой рост фондового рынка не только оправдывался, но и подавался как имманентный и необходимый фактор. В своих речах перед Конгрессом ${ }^{10}$ он объяснял, что фундаментальной причиной возрастающего динамизма экономики и подавления инфляции является новая фаза роста производительности, которая вызвала бурный рост инвестиций с 1993 года, особенно в высокотехнологичных отраслях. Растущая производительность вызывает экспансию путем механизма, который Гринспен

\footnotetext{
9 Роберт Шиллер подметил, что подобным образом ситуация развивалась и на других медвежьих рынках: «На пути к трем пикам рынка, которые случились после создания Федеральной резервной системы, - а именно пикам 1929, 1966 и 2000 годов, Федеральная резервная система каждый раз выступала с предупреждением, что рынок акций переоценен» (Shiller, 2005).

${ }^{10}$ Имеются в виду выступления Гринспена (Greenspan, 1998a) и (Greenspan, 1998b). Второе выступление перед Сенатом, а не перед Конгрессом.
} 
назвал virtuous cycle (замкнутый круг наоборот). Ожидания ускоряющегося роста производительности, связанные с технологическими прорывами, достигнутыми компаниями “Новой экономики”, оправдывают ожидания экстраординарного роста прибыли, простирающегося в далекое будущее... что приведет к еще большему росту курса акций» (Brenner, 2002).

Этот пример убедительно показывает, как трудно бывает регулятору оценить и реальное положение дел, и справедливый уровень цен на активы. Трише указывает на одну из основных причин этого - трудности с оценкой инфляции, ведь цены на активы зависят от будущих ожиданий инфляции и могут быть опережающим индикатором разгоняющегося роста цен (Trichet, 2003).

Мнения экономистов-теоретиков и регуляторов-практиков касательно политики сдерживания надувания пузыря при помощи монетарных инструментов сходятся не только в том, что это крайне сложно сделать в принципе. Ученые и политики-финансисты единодушны и в том, что основной рычаг, имеющийся в распоряжении центробанков, регулирование процентной ставки - не является тем механизмом, при помощи которого можно было бы корректировать финансовые пузыри, даже если бы возникло такое желание. Известный специалист по финансовым пузырям, ныне покойный Чарльз Киндлебергер, в частности, писал, что «тяжесть исторических свидетельств говорит о том, что монетарная политика могла бы смягчить пузыри, которые ведут к краху, но она не может устранить их полностью» (Kindleberger, 1989). Алан Гринспен неоднократно говорил о том же.

Итак, можно констатировать, что и Гринспен, и Бернанке, и Трише имеют весьма схожие теоретические убеждения: цены на активы лучше не регулировать.

На практике действовать они вынуждены в зависимости от того, что позволяет политическая ситуация. Сейчас трудно оценить, до какой степени Алан Гринспен верил в наступление «новой эры», но совершенно очевидно, что если бы он и задумал сдувать пузырь на американском фондовом рынке, то не нашел бы поддержки на самом верху. В своих мемуарах Гринспен цитирует Уильяма Макчесни, главу Федеральной резервной системы в 1950-1960-х годах, который утверждал, что роль ФРС состоит в том, чтобы приказать «унести чашу с пуншем, когда вечеринка только начинается» (Greenspan, 2008). Сам Гринспен «чашу с пуншем» не унес. Он недвусмысленно пишет о том, что проводимая им политика была единственно возможной в бытность президента Джорджа Буша-младшего - на сдувание пузыря тот бы не пошел. Как сформулировал Ричард Расселл (Richard Russell) ${ }^{11}$ в сентябре 1999 года: «...ясно, что власти не хотят, чтобы рыночные силы проявили себя, а точнее сказать, они сделают все, чтобы предотвратить это... Федеральная резервная система нацелена на то, чтобы бороться с медведями всеми своими силами... и в результате такой борьбы в конце концов медвежий рынок будет простираться дальше, чем можно было бы ожидать в противном случае» (Цит. по: Mahar, 2004, p. 316).

Таким образом, несмотря на формальную независимость глав центробанков от правительств в большинстве стран, включая Россию, желание монетарных властей скорректировать пузырь должно обязательно подкрепляться политической волей первых лиц страны.

\section{4. Возможные действия монетарных властей при сдувании финансового пузыря}

Вопрос о том, что могут и должны предпринять монетарные власти, когда пузырь стал сдуваться, является более дискуссионным. Одни считают, что власти должны исповедовать стратегию пассивного наблюдения. Аргумент «против» очевиден: в такой стране, например, как США, где практически каждый владеет акциями - через пенсионные планы и не только, схлопывание пузыря чревато серьезными социальными последствиями. Этот мотив не так

\footnotetext{
${ }^{11}$ Известный независимый финансовый аналитик, специалист по техническому анализу и циклам. Издает Тhe Dow Theory Letters.
} 
актуален для России, где процент населения, который играет на рынке акций или валютном рынке, не так высок, а пенсии слабо зависят от уровня цен на акции и облигации.

Другой вариант состоит в том, чтобы попытаться «сгладить» пузырь, то есть сдерживать падение завышенных рыночных цен активов до справедливых. Этого можно достичь, например, за счет «накачки» экономики деньгами: в этом случае справедливые цены подтянутся к завышенным рыночным из-за инфляции, и достигнутый уровень станет «нормальным». Если при этом регулятор пассивно наблюдал за надуванием пузыря, то такая политика называется асимметричной: когда все хорошо, государство самоустраняется от регулирования, когда дела идут неважно - спасает инвесторов.

Проанализируем плюсы и минусы второго варианта. Представим себе, что пузырь имеет место на рынке акций. Увеличение предложения денег, скорее всего, приведет к раскрутке инфляции, что в долгосрочной перспективе увеличит выручку и прибыль в номинальном выражении большинства компаний, а это, в свою очередь, сделает более обоснованными оценки акций, казавшиеся при прежних инфляционных ожиданиях завышенными. Инвесторы, вкладывавшиеся в такие акции, сочтут себя лучшими предсказателями будущего, чем более консервативные игроки. В долгосрочной перспективе это будет только усиливать безответственное поведение, что породит так называемую проблему moral hazard ${ }^{12}$. Примеров множество. Подобным образом можно квалифицировать действия правительства США по спасению заемщиков в ходе кризиса 2007 года. Таким образом, государство оказывается между двух огней - либо поощрять действия, приводящие к надуванию пузыря, либо жестоко наказывать «зарвавшихся» инвесторов, что может аукнуться масштабным финансовым кризисом.

Ситуацию усугубляет то, что в случае выбора стратегии «спасение» реальное спасение отнюдь не гарантировано. Во-первых, государство может дать частному сектору деньги, но не может контролировать, где они в конечном итоге окажутся. Посмотрим, например, на спасение финансовой системы России в ходе финансового кризиса в 2008 году: рублевая ликвидность, которой была накачана система, оказалась на валютном рынке, что только усилило давление на рубль. Во-вторых, предложение денег государством (за исключением бумажных денег, которые печатаются физически), регулируется лишь косвенно - через ставку рефинансирования и нормативы резервирования. В то, что мы привыкли по-простому называть деньгами, входит и кредитная масса (агрегат М2). В случае разрастания кризиса плохих долгов и масштабных списаний капитала банками кредитные институты могут работать только на возврат старых кредитов и прекратить выдавать новые (нормативы резервирования не позволяют, риски трудно оценить и т.п.), как это и произошло в мировой финансовой системе в 2008 году. А ослабление нормативов резервирования - это увеличение рисков системы. Таким образом, денежная масса в экономике может сокращаться, даже невзирая на экспансионистскую монетарную политику властей. Получается замкнутый круг. Чем глубже финансовый кризис, тем меньше вероятность, что план по спасению окажется удачным.

\section{5. Выводы: возможные подходы российского центробанка к регулированию финансовых пузырей}

На наш взгляд, макроэкономическое регулирование финансовых пузырей должно быть в первую очередь превентивным: регулятору в лице Центробанка нужно с осторожностью пользоваться таким инструментом, как низкая реальная процентная ставка, чтобы не создавать макроэкономических предпосылок для надувания пузыря. Когда пузырь уже надулся, «схлопывать» его, по нашему мнению, нецелесообразно. Причины этого следующие.

\footnotetext{
12 Перевод этого термина на русский язык не устоялся. Корректными, на мой взгляд, являются следующие из предложенных вариантов: моральная угроза, моральный риск, риск бессовестного поведения, риск снижения ответственности.
} 
- «Насильственное» сдувание пузыря есть форма регулирования цен на активы, что представляется чрезмерным вмешательством государства в экономику при рыночных экономических отношениях; несмотря на масштабные пузыри в экономике США в конце XX века, ученые по-прежнему считают, что Центробанк должен таргетировать инфляцию и/или экономический рост, но не цены активов.

- Регулятор может ошибаться, диагностируя факт экономического пузыря.

-У властей нет хорошо работающих инструментов, чтобы регулировать пузырь, в частности, он не обязательно начнет схлопываться при повышении процентной ставки и уж тем более - при «словесных интервенциях».

- Нет никаких гарантий, что центробанку удастся сдуть пузырь плавно, без широких макроэкономических последствий; при искусственном «протыкании» пузыря существует опасность лавинообразного падения, тогда как при отсутствии вмешательства могло иметь место плавное снижение, которое было бы переварено рынком безболезненно. По всей видимости, прав Гелбрейт, который сказал: «Пузырь проткнуть легко. Но проткнуть его иголкой так, чтобы он сдулся медленно, - очень тонкое дело» (Galbraith, 1975).

Последний аргумент особенно актуален для таких стран, как Россия, где мы наблюдаем резкие масштабные падения на фондовом рынке и без вмешательства со стороны финансовых властей.

С другой стороны, негативные последствия имеются и у обратной политики сдерживания схлопывания пузыря.

-У финансового регулятора нет достаточно тонких рычагов такого сдерживания.

- Как правило, основным инструментом сдерживания схлопывания пузыря является предоставление игрокам финансирования на льготных условиях, что чревато кратко- и долгосрочными негативными последствиями.

- Краткосрочные последствия могут состоять в том, что деньги окажутся не там, где планировало государство. Это проверено на опыте многих стран.

- Долгосрочные последствия заключаются в стимулировании безответственного поведения среди участников рынка: если во время кризиса некоторые институты начинают спасать, например, по принципу он «слишком большой, чтобы обанкротиться» (to big to fail), это стимулирует еще более рисковое поведение экономических агентов в будущем. Возникает риск снижения отвественности (moral hazard).

- Наконец, имеется негативный мировой опыт сдерживания коррекции пузырей, который показал, что в этом случае начало экономического роста может быть отсрочено. Это, например, имело место в Японии, где пузырь схлопнулся в 1990 году. В этой стране фондовый рынок и цены на недвижимость падали медленнее, чем это произошло бы, как полагают ученые, в случае отсутствия рычагов сдерживания, однако тем самым экономика не была очищена от плохих активов, и не был создан плацдарм для нового роста. Масштабный экономический рост практически так и не возобновился.

Таким образом, на наш взгляд, оптимальное соотношение плюсов и минусов имеет политика мягкого превентивного сдерживания, а если она не помогла, то предпочтительным становится пассивное наблюдение: принудительное схлопывание или, напротив, сдерживание сдутия финансового пузыря могут обернуться тяжелыми и непредсказуемыми последствиями.

\section{Список литературы}

1. Гринспен А. Эпоха турбулентности. - М.: Альпина Бизнес Букс, 2008.

2. Киндлебергер Ч. Мировые финансовые кризисы: мании, паники и крахи. - С.-Пб: Питер, 2010.

3. Barksy, R., and De Long, B. (1990), Bull and Bear Markets in the Twentieth Century, Journal of Economic History, 2(50) (1990). 
4. Bernanke, B., and Kuttner, K. (2005), What Explains the Stock Market's Reaction to Federal Reserve Policy? Journal of Finance, 2(60) (2005).

5. Bernanke, B., and Kuttner, K. (2005), What Explains the Stock Market's Reaction to Federal Reserve Policy? Journal of Finance, 3(60) (2005).

6. Brenner, R. (2002), The Boom and the Bubble: The US in the World Economy. - London: Verso.

7. De Long, B., and Shleifer, A. (1991), The Stock Market Bubble of 1929: Evidence from Closed-end Mutual Funds, Journal of Economic History, 3(51) (1991).

8. Donaldson, G., and Kamstra, M. (1996), A New Dividend Forecasting Procedure That Rejects Bubbles in Asset Prices: The Case of 1929's Stock Crash, Review of Financial Studies, 2(9) (1996).

9. Faber, M. (2008), Tomorrow's Gold. Asia's Age of Discovery. - Hong Kong: CLSA Books.

10. Galbraith, K. (1975), The Great Crash 1929. - London: Penguin Books.

11. Greenspan Al. (1998a), An Update on Economic Conditions in the United States Testimony Before the Joint Economic Committee, U.S. Congress, June 17, 1999.. URL:http://www.federalreserve.gov/boarddocs/testimony/1998/19980610.htm.

12. Greenspan A. (1998b), The Federal Reserve's Semiannual Monetary Policy Report - Before the Committee on Banking, Housing, and Urban Affairs, U.S. Senate July 21, 1998. URL: http://www.federalreserve.gov/boarddocs/hh/1998/july/testimony.htm.

13. Greenspan A. (1999), Monetary Policy and the Economic Outlook - Testimony Before the Joint Economic Committee, U.S. Congress, June 17, 1999. URL: http://www.federalreserve.gov/boarddocs/testimony/1999/19990617.htm.

14. Greenspan A. (2002), Economic Volatility, Speech at a symposium sponsored by the Federal Reserve Bank of Kansas City, Jackson Hole, Wyoming, August 30, 2002.

15. Mahar, M. (2004), Bull! A History of the Boom and Bust. - N.-Y.: Harper Collins Publishers.

16. McGrattan, E., and Prescott, E. (2003), The 1929 Stock Market: Irving Fisher Was Right, Federal Reserve Bank of Minneapolis Research Department Staff Report 294. December 2003.

17. Mishkin F. and White, E.. What Should the Fed Do about Stock Market Crashes: A Historical Perspective. www0.gsb.columbia.edu/faculty/fmishkin/PDFpapers/03milken.pdf.

18. Napier, R. (2007), Anatomy of the Bear. - Petersfield, Hampshire, UK: Harriman House.

19. Rappoport, P., and White, E. (1993), Was There a Bubble in the 1929 Stock Market? Journal of Economic History, 3(53) (1993).

20. Rigobon, R., and Sack, B., (2003), Measuring The Reaction Of Monetary Policy To The Stock Market, Quarterly Journal of Economics, (2003).

21. Rubin, R., and Wesberg, J. (2004), In an Uncertain World. Though Choices from Wall Street to Washington. - N.-Y.: Random House.

22. Shiller, R. (2005), Irrational Exuberance. - N.-Y.: Brodway Books.

23. Sirkin, G. (1975), The Stock Market of 1929 Revisited: A Note, Business History Review, 2(49) (1975).

24. Trichet, J.-C. (2003). Asset Price Bubbles and Their Implications for Monetary Policy and Price Stability. In W.C. Hunter, .G.G. Kaufman and M. Pomerleano (eds.) Asset Price Bubbles: The Implications for Monetary, Regulatory and International Policies, Cambridge, MA: MIT Press.

25. Trichet, J.-C. (2005), Asset Price Bubbles and Monetary Policy, Speech in Singapore, 8 June 2005, Singapore.

26. White, E. (1990), The Stock Market Boom and Crash of 1929 Revisited, Journal of Economic Perspectives, 2(4) (1990). 